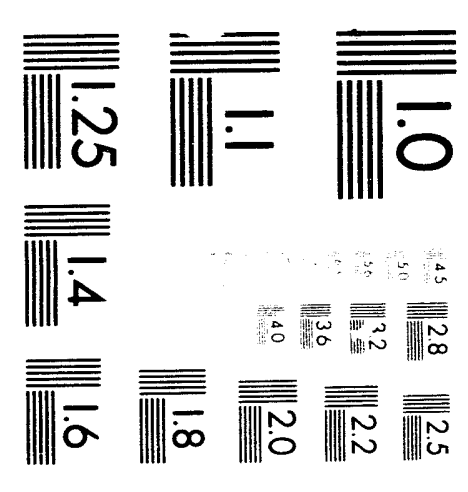



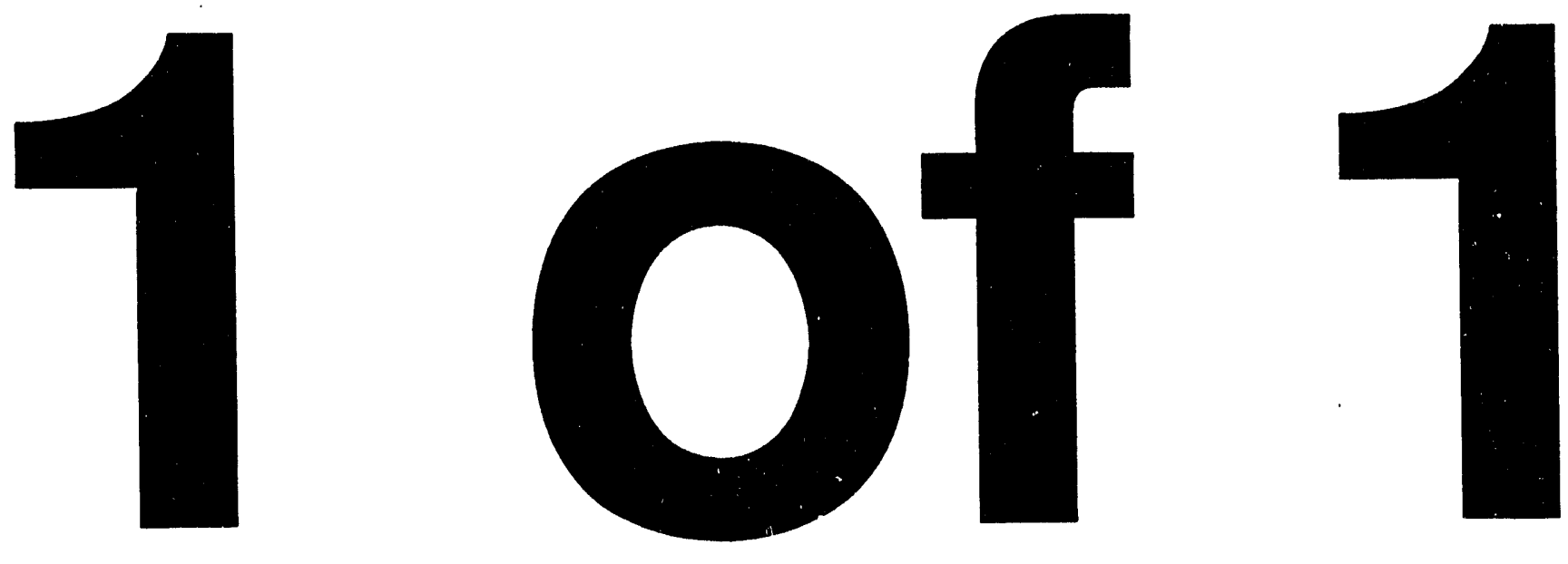


\title{
GRAUITY SAG OF SANDUICH PANEL ASSEMBLIES AS APPLIED TO PRECISION CATHODE STRIP CHAMBER STRUCTURAL DESIGN
}

\author{
John Horvath, LLNL
}

September 16, 1993

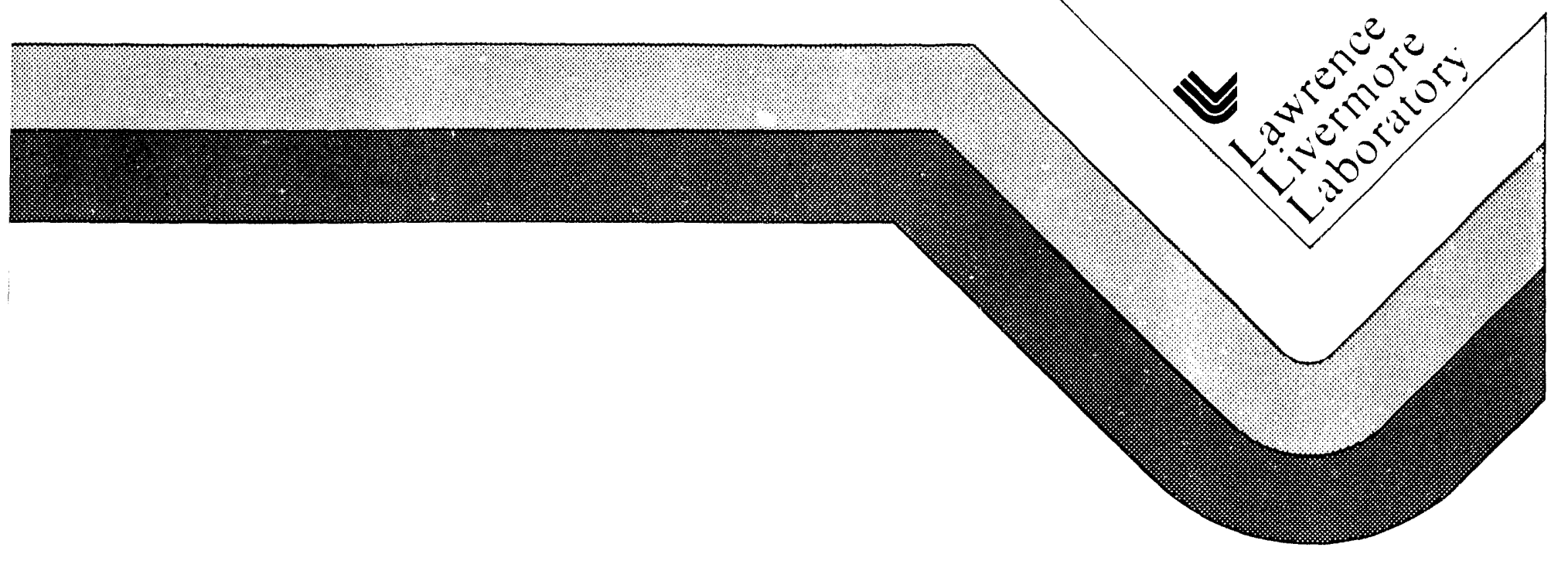

$$
y+\cdots
$$




\section{DISCLAIMER}

This doument was prepared as an account of work sponsored by an agency of the United States Ciovernment. Ne'the'? the United States Government nor the University of California nor any of their employees, makes any warrants express or implied, or assumes any legal liability or responsibility for the accuracy, completeness, or usetulness of an information, apparatus, product, or process disclosed, or represents that its use would not infringe privately own nghts. Reference herein to any specific commercial products, process, or service by trade narne, trademark, manutacturer, ir otherwise, does not necessarily constitute or imply its endorsement, recommendation, or favoring by the United States Government or the University of California. The views and opinions of authors expressed heren do not necessarily state or reflect those of the United States Government or the University of California, and shall not be used for advertising or product endorsement purposes

AUSPICES

Worn performed under the aupices of the U. S. Department of Energy by Lawrence Livermore National Laboratory under contract W-7405-ENG-48. 


\title{
Gravity Sag of Sandwich Panel Assemblies
}

\author{
As Applied To \\ Precision Cathode Strip Chamber Structural Design \\ John Horvath \\ Lawrence Livermore National Laboratory
}

July 12, 1993

\begin{abstract}
:
The relauonship between gravity sag of a precision cathode strip chamber and its sandwich panel structural design is explored parametrically. An algorithm for estimatung the dominant component of gravity sag is defined. Graphs of normalized gravity sag as i function of gap frame width and material, sandwich core edge filler width and material. panel skin thickness. gap height, and suppor location are calculated using the gravity sag algorithm. The stuctural importance of the sandwich-to-sandwich "gap frame" cornection is explained.
\end{abstract}

\section{RECEIVED JAN $2>1994$ OSTI}


How to calculate the stiFFness of A STACK OF SLAB:

$1 / 9$

$$
\begin{aligned}
& \text { STIFFNESS OC ONE SOLID SLAB } \\
& \text { WITH RECTANGULAR CROSS-SEC } \\
& I_{\text {SLAB }}=\frac{b h^{3}}{12} \neq
\end{aligned}
$$$$
\text { WITH RECTANGULAR CROSS-SECTION }
$$

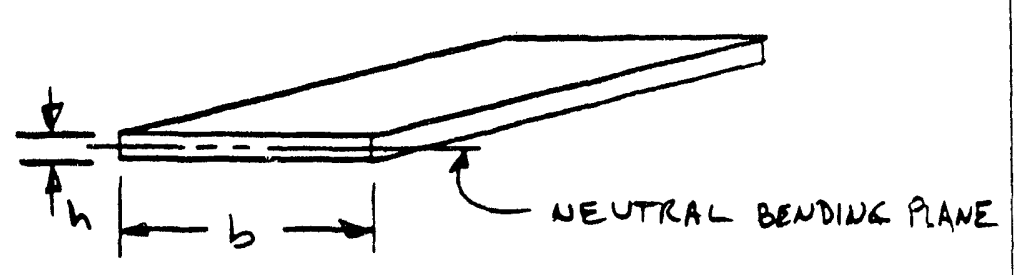

NOTE:

$I_{\text {sLab }}$ is tiTHE "AREa moment of inertial or the cross - section cALCULATED WITH RESPECT TO THE CENTROID OF THE SEETION.

the definition of "I" is,

$$
I=\int_{\text {AREA }} y^{2} d A \text { WHERE } y=\begin{aligned}
& \text { DISTANCE FROM THE } \\
& \text { NEUTRAL PLANE TO } \\
& \text { ELEMENT } D A
\end{aligned}
$$

The "Inertia". Of a rectangular $b \times h$ cross-section is,

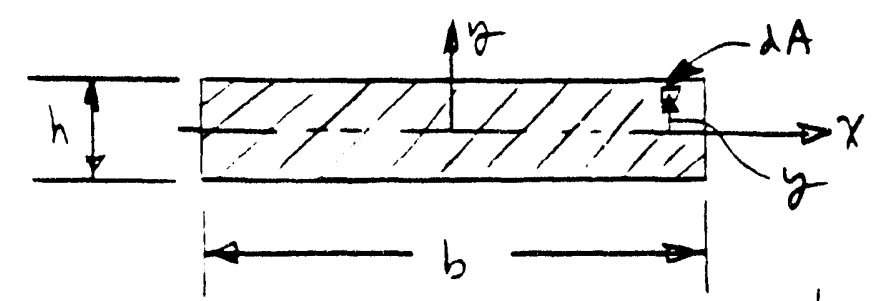

THE VERTICAL COORDINATE OF THE CENTROID IS ALSO CALLED THE NEUTRAL PLANE

$$
\begin{aligned}
& I=\int_{A R E A} y^{2} d A_{R E A}=\int_{0}^{b} \int_{-\frac{h}{2}}^{\frac{h}{2}} y^{2} d y d x \\
& I=\left[\int_{-\frac{h}{2}}^{\frac{h}{2}} y^{2} d y x\right]_{0}^{b}=\left[\left[\frac{y^{3}}{3}\right]_{-\frac{h}{2}}^{\frac{h}{2}} x\right]_{0}^{b} \\
& I=\frac{(2) h^{3} b}{(8)(3)} \\
& I_{\text {RECTANGLE }}=\frac{b h^{3}}{12}=\text { MOMENT OF INERTIA OF ONE RECTANGULAR SLAB }
\end{aligned}
$$

1 


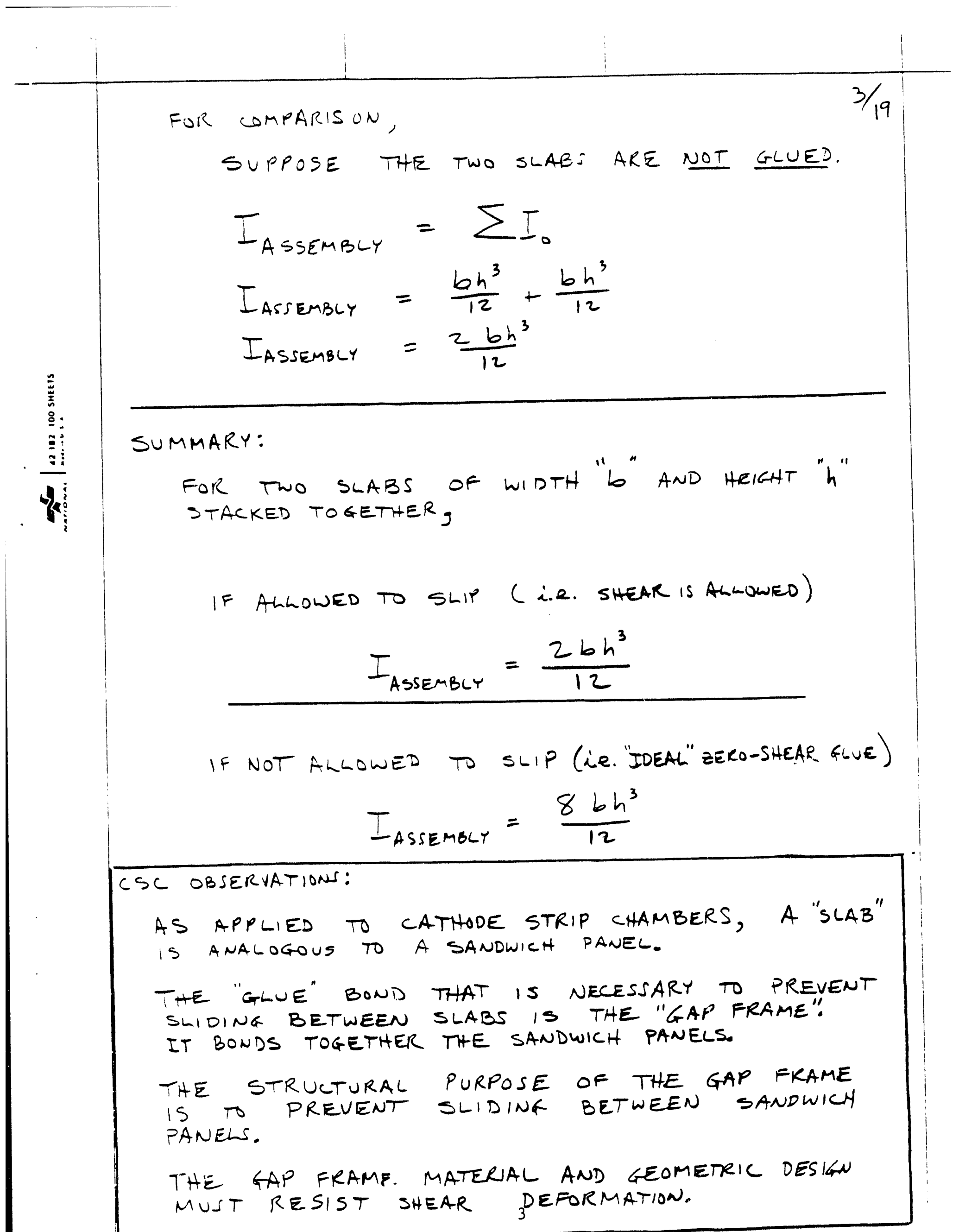


STIFNESS OF A SANDWICH PANEL

THE core of A sandWICH PANEL behaves like the "WEB" OF AN I-BEAM, PREVENTING SLIDING

BETWEEN TOP AND BOTTOM FLANGES.
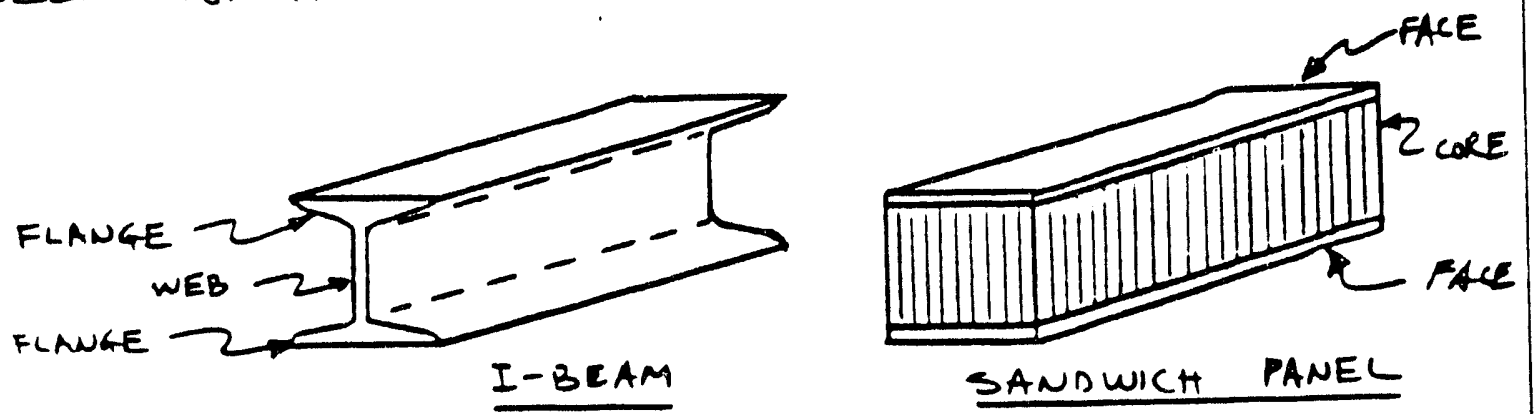

The facings of a sandwich panel used as a beam act similarly to the flanges of an I-beam by taking the bending loads - one facing in compression and the other in tension. Expanding this comparison further, the honeycomb core corresponds to the web of the l-beam. This core resists the shear loads,

increases the stiffness of the structure by spreading the tacings apart. but unlike the I-beam's web. gives continuous suppont to the flanges or facings. The core-10-skin adhesive ngidly joins the sandwich components and allows them to act as one unit with a high torsional and bending rigidity.

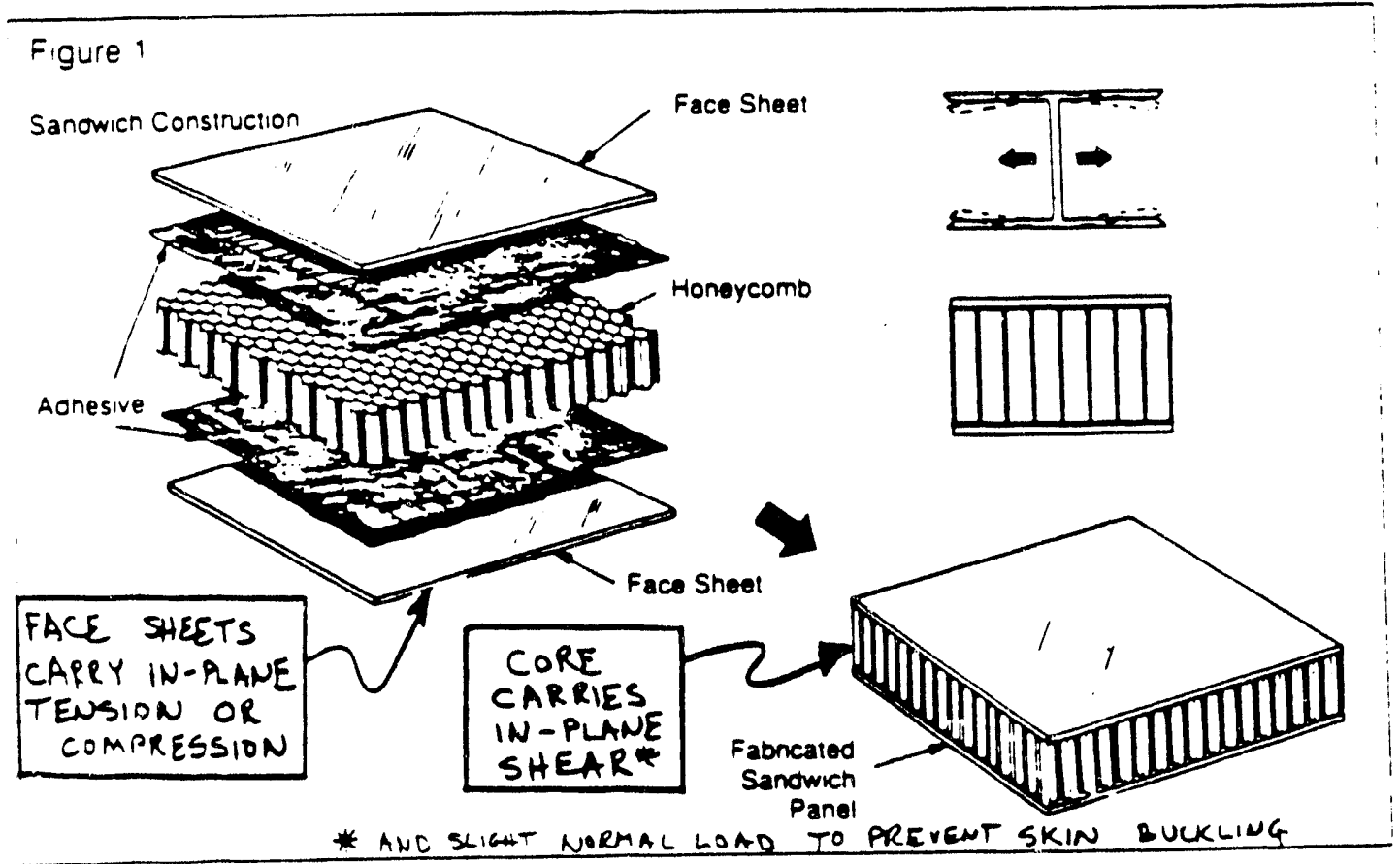




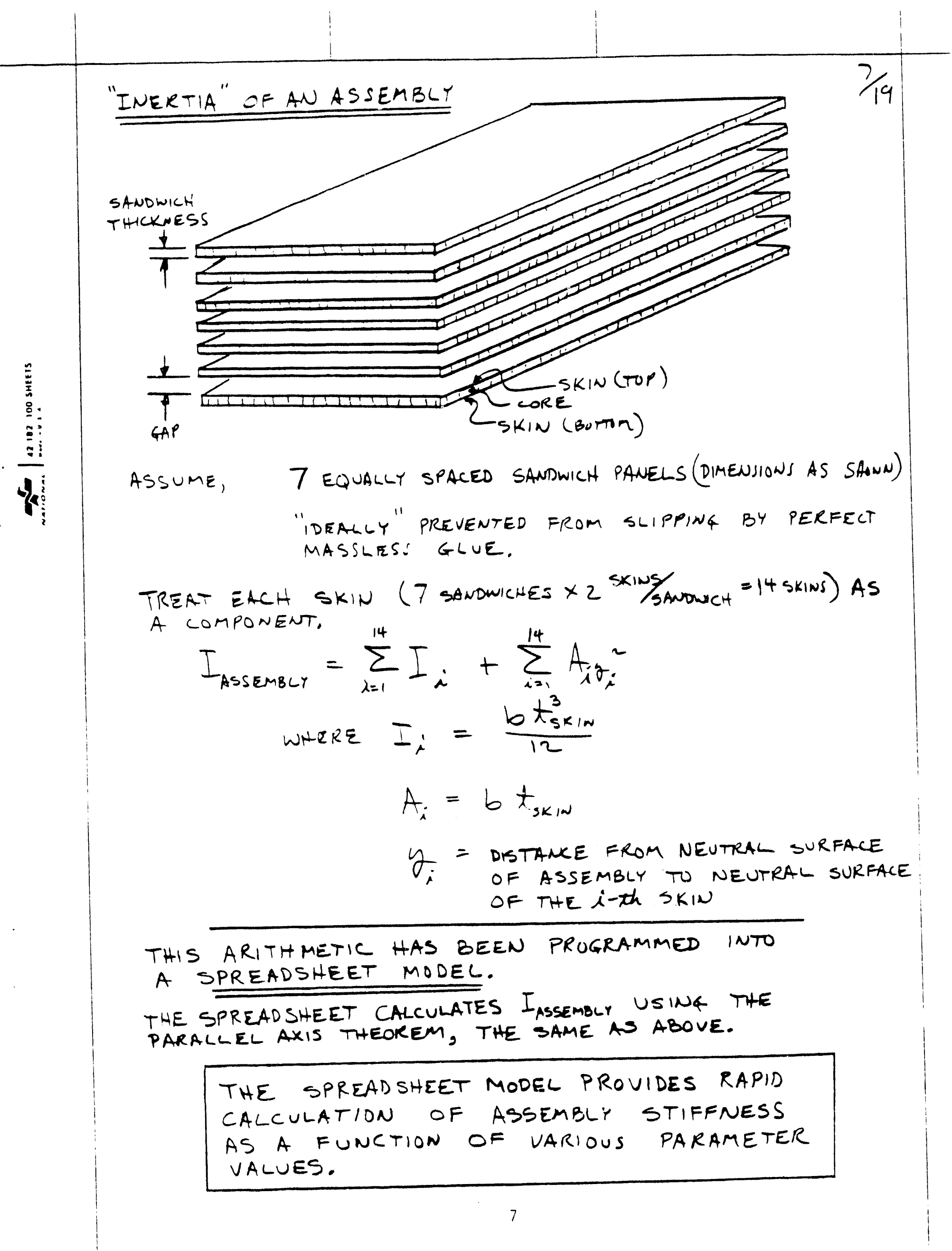


Normalized Moment of Inertia

Vs. Skin Thickness, Gap Thickness, \& Gap "Slip"

Seven $20.0 \mathrm{~mm}$-thick Sandwich Panels

("ideal" zero-shear glue assumed)

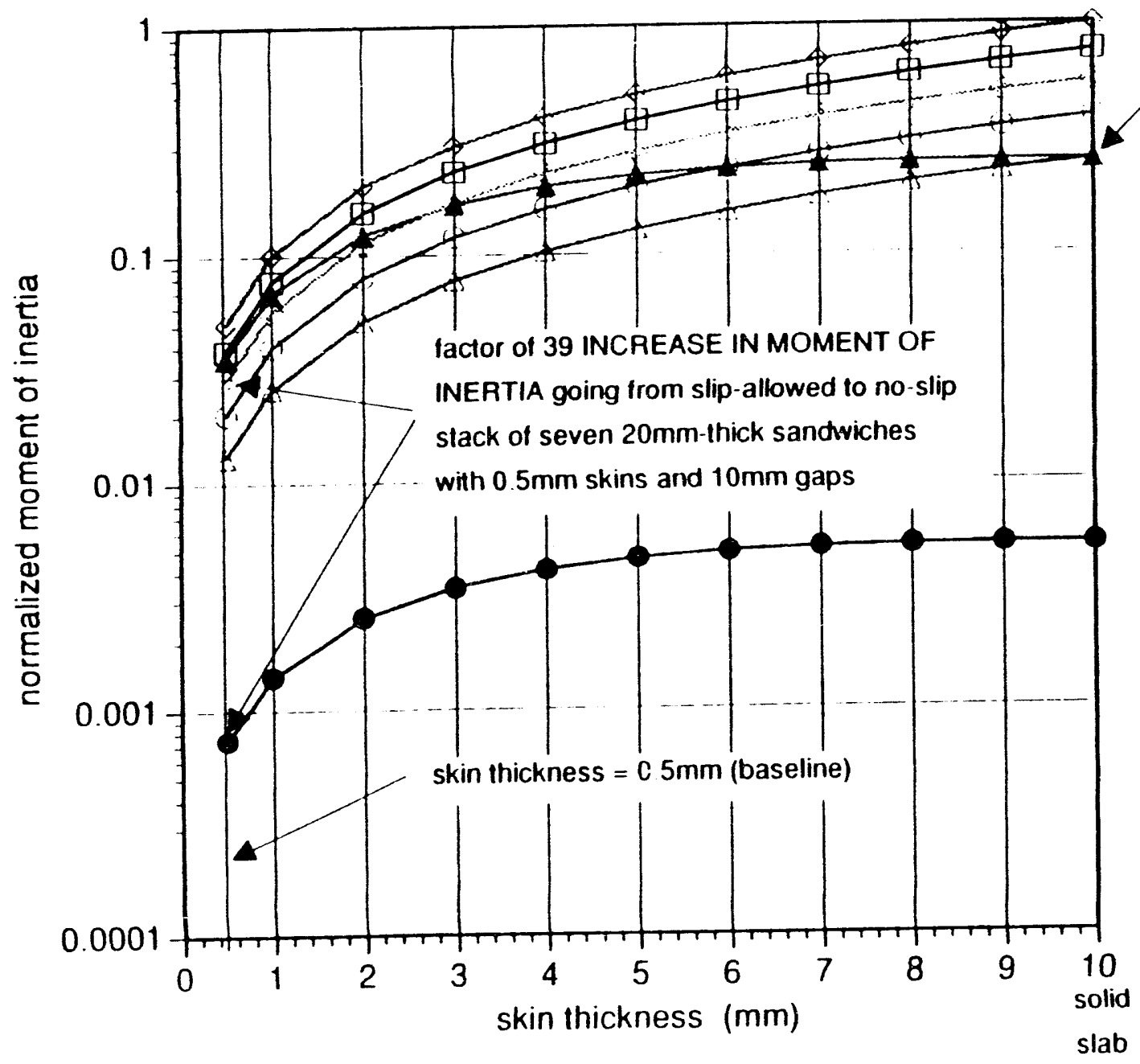

"n-squared" Rule-ot-Thumb

is 6xact for a "solid slab"

(skin $=10 \mathrm{~mm}$, sandwich $=20 \mathrm{~mm}$, gap $=0 \mathrm{~mm}$ )

$\rightarrow$ gap $=20.0 \mathrm{~mm}$ ("IDEAL" glue)

Ð gap $=15.0 \mathrm{~mm}$ ("IDEAL" glue)

....... gap $=10.0 \mathrm{~mm}$ ("IDEAL" glue)

gap $=5.0 \mathrm{~mm}$ ("IDEAL" glue)

gap $=0.0 \mathrm{~mm}$ ("IDEAL" glue)

— "n-squared" Rule-of-Thumb

- ANY gap size (SLIP ALLOWED) 


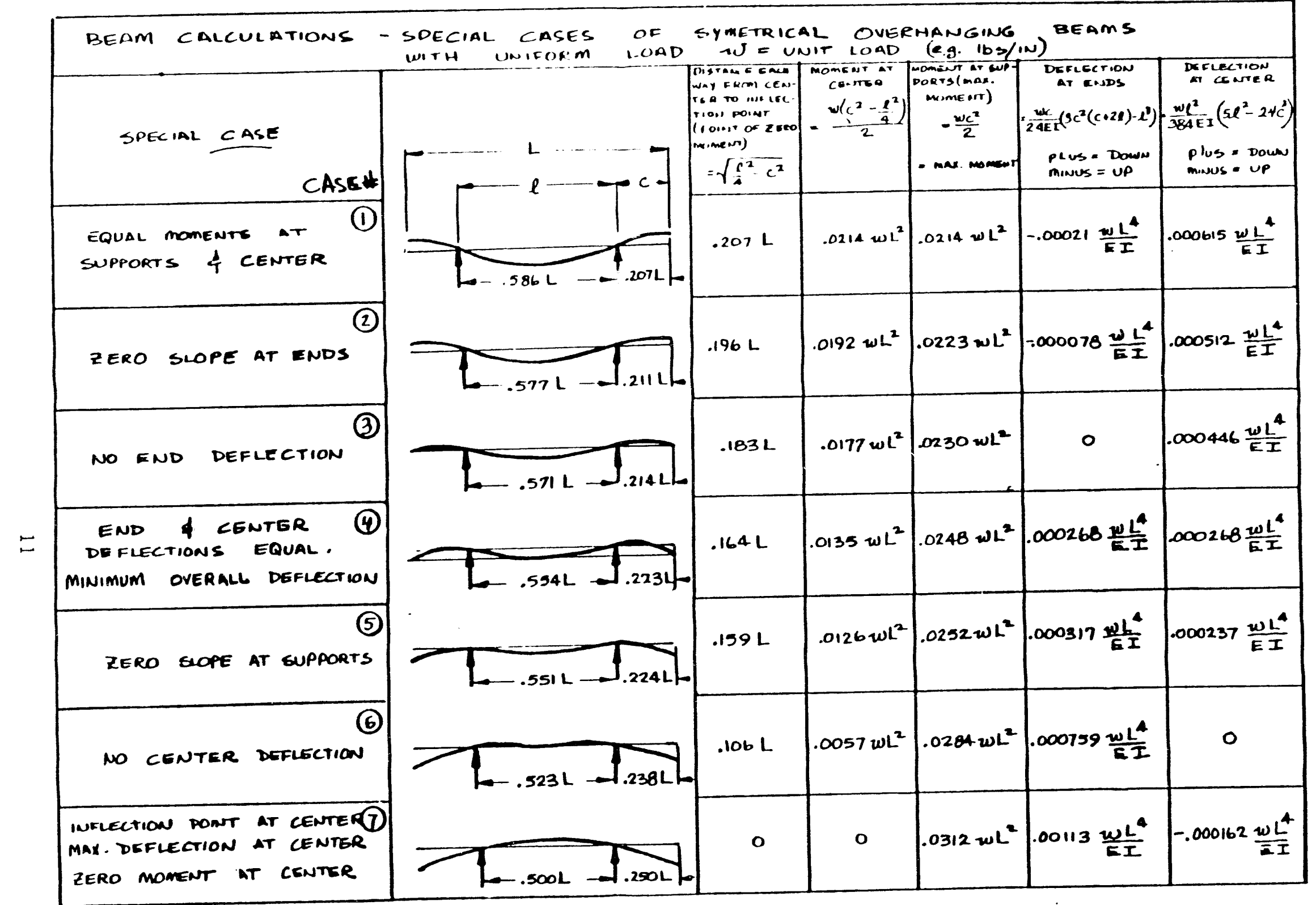


THE EFFECT OF GAP FRAMES ON DEFLECTION

IN THE DREUIOUS ANALYSIS THE STACK OF SANDWICH PANELS (WITH GAPS BETWEEN PANELS) WAS ASSUMED BONDED ACROSS THE GAPS WITH "IDEAL" MASSLESS GLUE.

In MECHANICS, THIS BENDING ANALTSIS ASSUMPTION

IS STATED AS "CROSS-SECTIONS REMAIN FLAT DURNA BENDING" FOR PLANE BENDING,

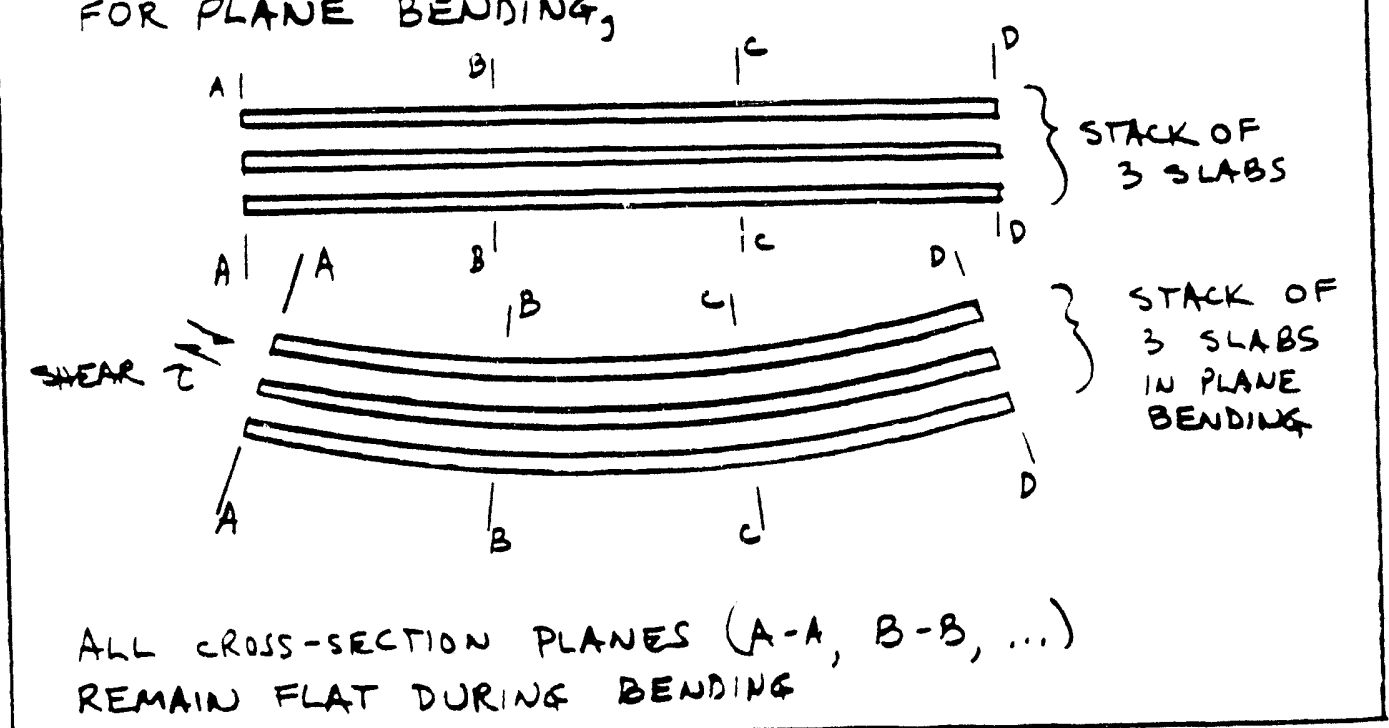

TO ACHIEUE THIS LINKING BETWEEN SLABS THE GAPS MUST BE SPANNED AT SUFFICIENT LOCATIONS AND IN a MANNER that resists tHE SHEAR lOAD INDUCED BETWEEN SLABS.

SHEAR bETWEEN SLABS CAUSES THE ABOVE SECTION PLANES TO WARP. THIS RESULTS IN AN ADDITIONAL COMPONENT of SAG CALLED "SHEAL DEFLECTION".

THE SANDWICH PANELS ARE LIWKED TOGETHER INTO A "SANDWICH OF SANDWIGHS" BY THE GAP FKAME. IDEALM THE GAP FRAME SHOULD PREVENT SHEAR DEFOKMATION (SLIPPING).

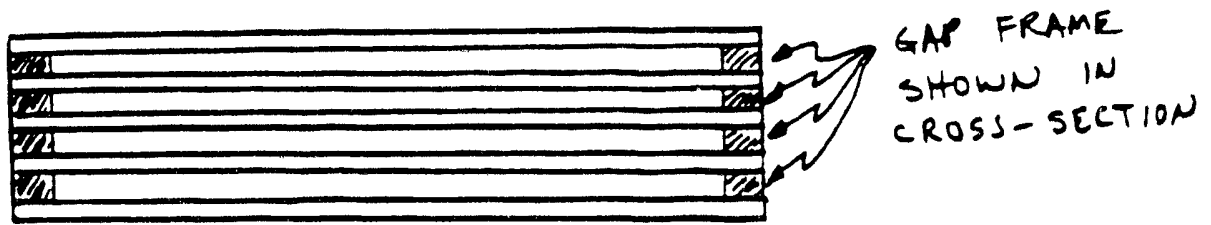

THE EEFECT OF GAP FRAME WIDTHS AAND MATERIALS ON ASSEMBLY GRAVITY SAG IS CALCULATED USING ANOTHER SPREADSHEET 13 AS FOLLOWS: 


\section{Normalized Gravity Sag}

Vs. Gap Frame Width \& Gap Frame Material

Seven 20.0mm-thick Sandwich Panels, No Core Edge Filler, Skin Thickness $=0.5 \mathrm{~mm}$, Gap Height $=10 \mathrm{~mm}$, NO SLIP ALLOWED

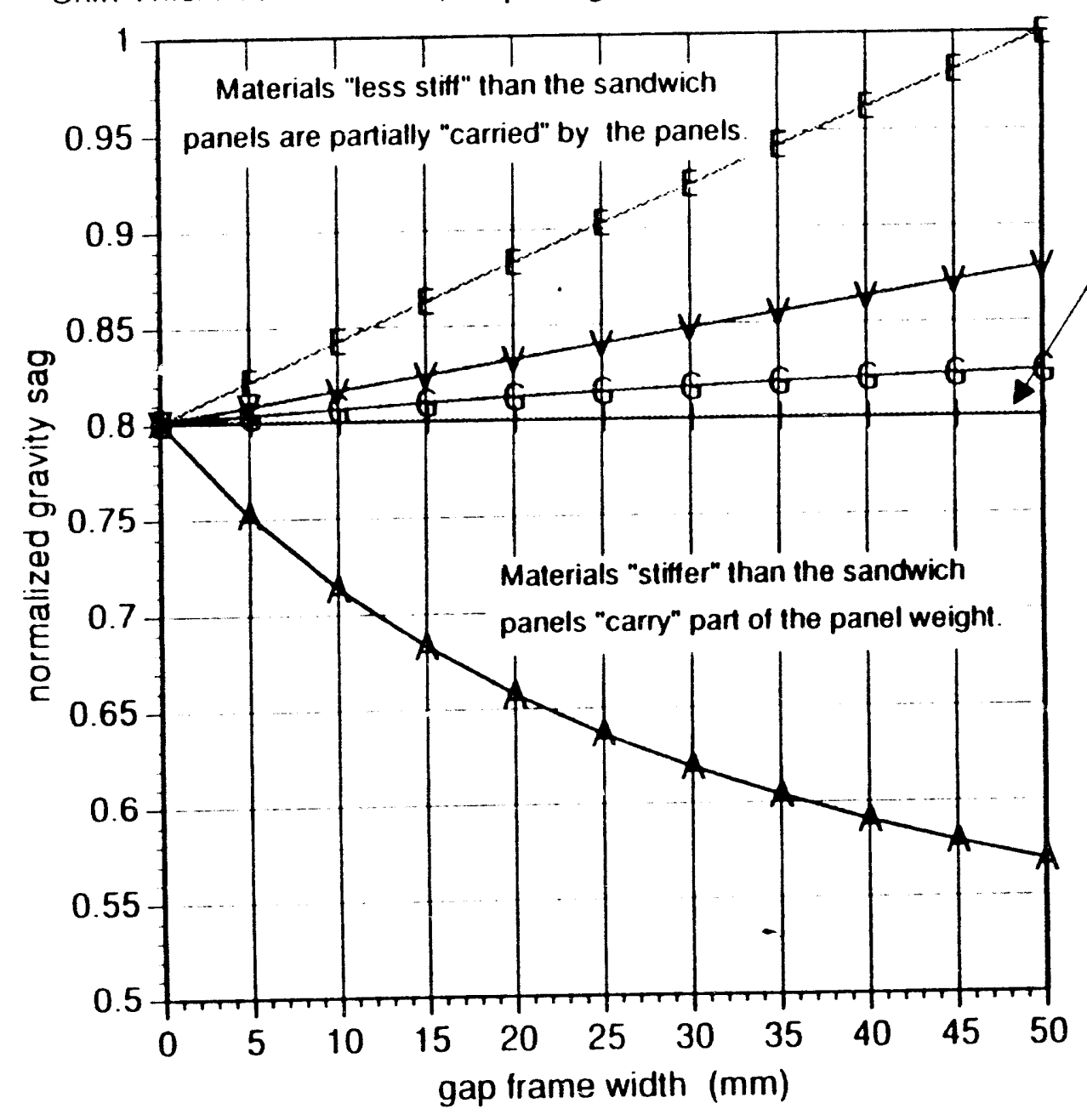

The "IDEAL" gap frame material adds no weight to the assembly and ALLOWS NO SLIP (no shear deflection) between panels

E... epoxy gap frame

$+\quad$ "Vinny's" gap frame

G G10 gap frame

† "IDEAL" glue gap frame

A aluminum gap frame

file: gfvmat base

jah $7 / 12 / 93$ 


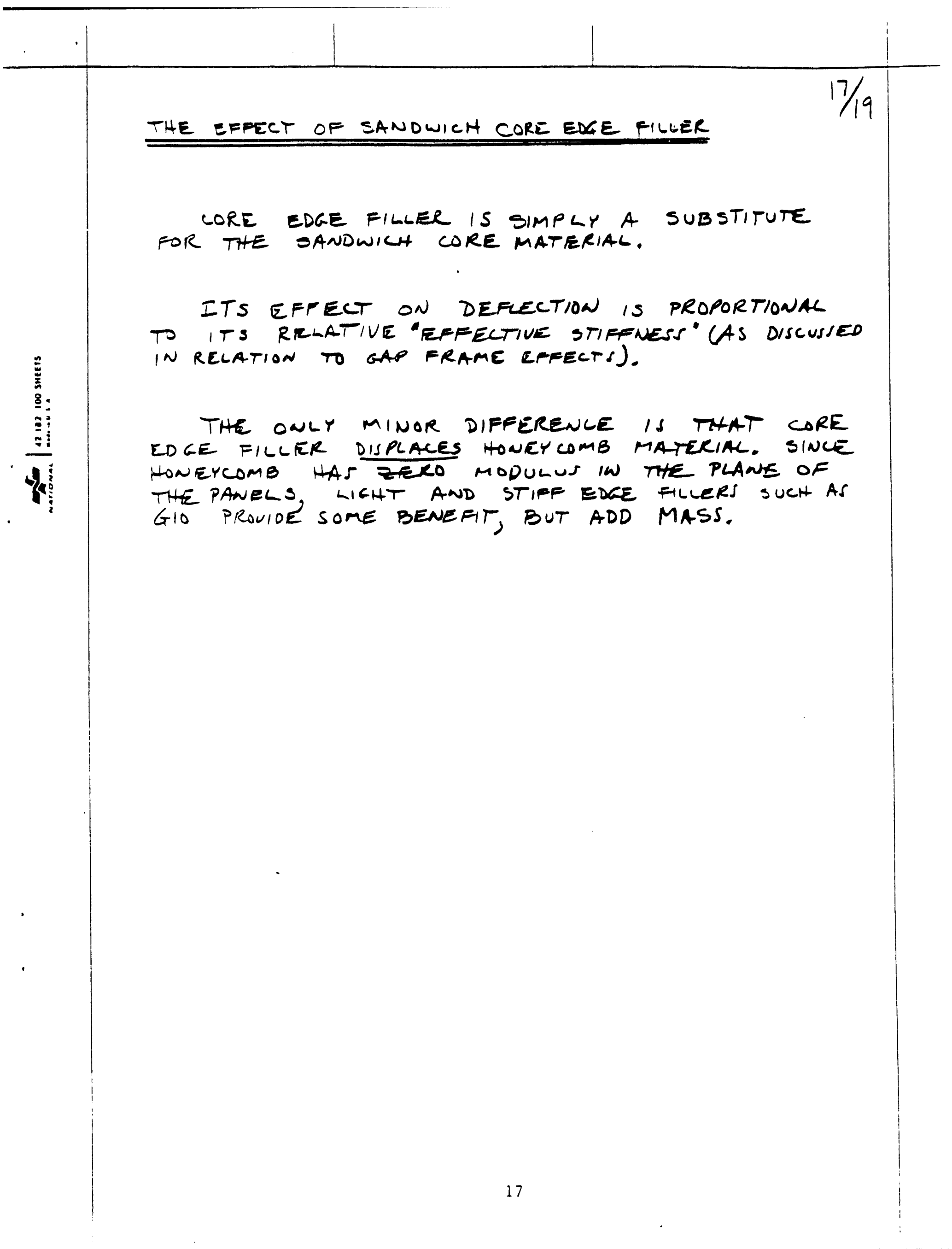




\section{Assumed Material properties}

The follou ing material properties were used in the normalized gravity sag calculations:

\begin{tabular}{c|c|c|c|c} 
material & $\begin{array}{c}\text { elastic modulus } \\
(\mathrm{psi})\end{array}$ & $\begin{array}{c}\text { mass density } \\
\left(\mathrm{lb} \mathrm{sec} 2 / \mathrm{in}^{\wedge} 4\right)\end{array}$ & $\begin{array}{c}\text { elastic modulus } \\
(\mathrm{MPa})\end{array}$ & $\begin{array}{c}\text { mass density } \\
\left(\mathrm{g} / \mathrm{cm}^{\wedge} 3\right)\end{array}$ \\
\hline G1(1) laminate & $3,300,000)$ & 0.000180 & 22,759 & 1.926 \\
\hline epoxy & $4(00,000$ & 0.000111 & 2.759 & 1.190 \\
\hline "Vinny" & 98,395 & 0.000039 & 679 & 0.420 \\
\hline aluminum & $1(1,0)(00.000$ & 0.000254 & 68,966 & 2.718 \\
\hline Nomex core & $\cdots$ & 0.000003 & $\cdots$ & 0.029
\end{tabular}

\section{Effect of Support locations}

The normalized gravity' sag graphs assume some constant support point locations. The chamber mass is assumed to be uniformly distributed along its length. The chart of beam deflection expressions shows that the maximum gravity sag is reduced by a factor of $4 \times$.6. i.e. $15 / 3 \times 4) /(1).(1)(1268$. by going from support at the extreme ends to support at points $11.223 \mathrm{~L}$ from the ends. Actual chamber sag will fall between these limits to the extent that weight is evenly distributed along the chamber length and shear deflection is prevented by proper panel-to-panel connection.

\section{Conclusion.}

The magnitude of chamber sag is highly dependent on chamber support location and devign of the gap frame. The gap between sandwich panels must be able to resist shear deformation. The major component of gravity sag is due to beam bending if shear deflection cun be avoided. Gravity sag increases by a factor of 39 going from an "ideal" sheir connection to slip-allowed between sandwich panels.

The mechanical connection between panels (gap frame and posts) will determine the magnitude of additional gravity sag introduced due to shear deflection. The design parameter that influence this value are the geometry of the gap frames around the perimeter of the panel, its mechanical properties, and the reliability of the panel-to-panel attachment technique (preloaded bolts, adhesives, pins, etc.) 

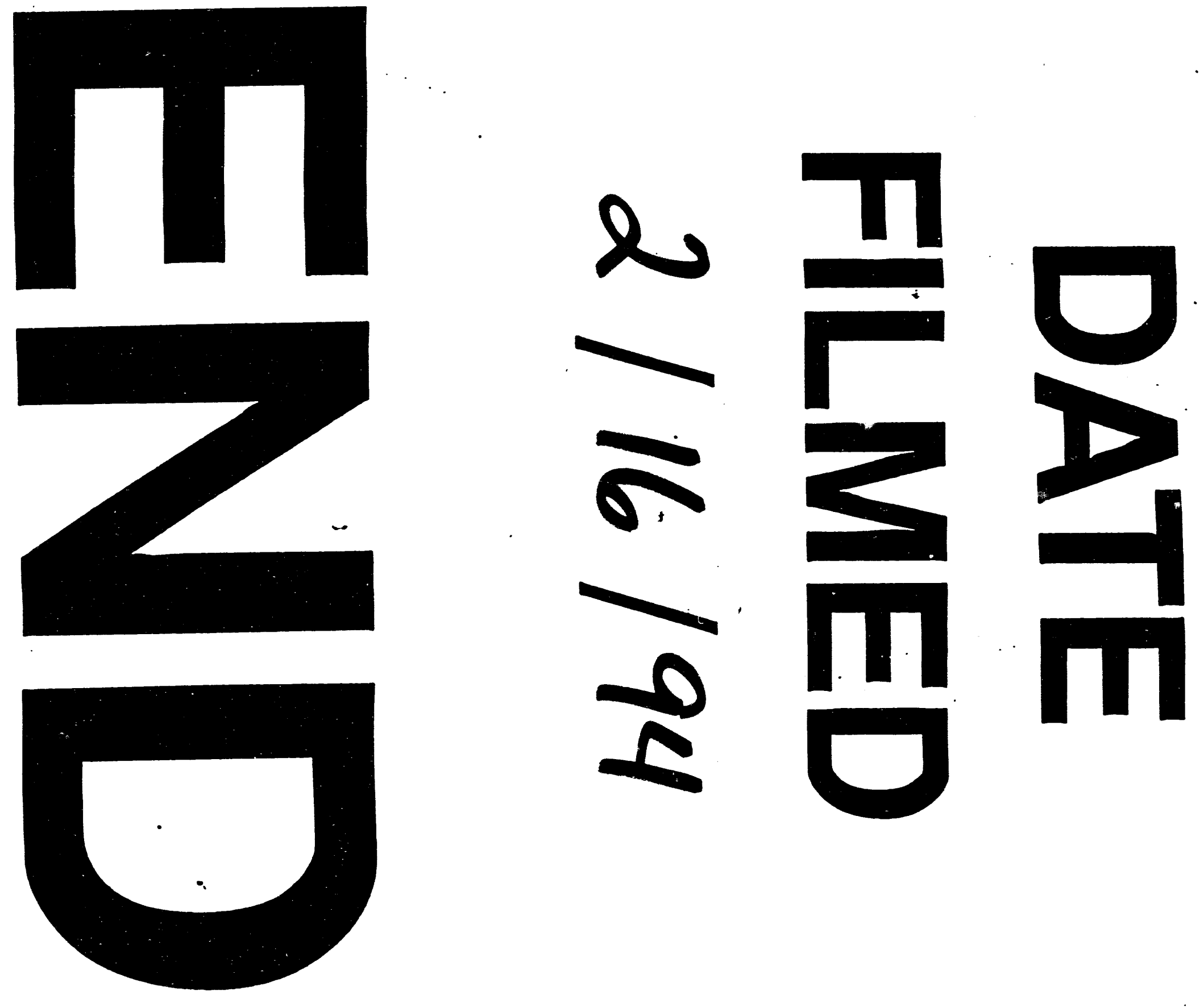
